\title{
Progress on $\mathrm{Nme}$ (NDP kinase/Nm23/Awd) gene family-related functions derived from animal model systems: studies on development, cardiovascular disease, and cancer metastasis exemplified
}

\author{
Tien Hsu • Patricia S. Steeg • Massimo Zollo • Thomas Wieland • \\ On behalf of the steering committee on Nme-related \\ research and the organizers of the International \\ Congresses of the NDP Kinase/Nm23/awd Gene Family
}

Received: 2 December 2014 / Accepted: 10 December 2014 /Published online: 15 January 2015

(C) Springer-Verlag Berlin Heidelberg (outside the USA) 2015

The enzyme nucleoside diphosphate kinase (NDP kinase or NDPK) was discovered in the 1950s as biochemical activity that removes the terminal phosphate from a nucleoside triphosphate (NTP) and adds it to a nucleoside diphosphate (NDP). Thus, the correct biochemical name for the enzyme is NTP/NDP transphosphorylase, and it is generally regarded as a housekeeping enzyme required for nucleotide homeostasis. At least four of the ten Nme gene family products (Nme 1-

All authors contributed equally.

T. Hsu $(\bowtie)$

Department of Medicine, Boston University School of Medicine,

Boston, MA 02118, USA

e-mail: tienhsu@ncu.edu.tw

\section{T. Hsu}

Institute of Systems Biology and Bioinformatics, National Central University, Jhongli, Taiwan

\section{P. S. Steeg $(\bowtie)$}

Women's Cancers Section, Laboratory of Molecular Pharmacology, Center for Cancer Research, National Cancer Institute, Building 37, Room 1122, National Institutes of Health, Bethesda, MD 20892, USA

e-mail: steegp@mail.nih.gov

\section{Zollo $(\bowtie)$}

Department of Molecular Medicine and Medical Biotechnology, University of Naples Federico II, Via Pansini 5, Naples, Italy

e-mail: massimo.zollo@unina.it
Nme4), also called group I Nme proteins, carry that enzymatic activity. A far more complex story was started in the 1990s when it became evident that enhanced cancer metastasis was linked to reduced expression of a gene named $n m 23$, which turned out to be identical to human Nme1= NDPK A. To date, the function of Nmel underlying its metastasis suppressor activity has not been clarified. It is hoped that fundamental cellular and molecular insights into the role of NDP kinase/

\section{Zollo}

CEINGE, Centro di Ingegneria Genetica Biotecnologie Avanzate, Università di Napoli Federico II, Via Sergio Pansini 5, 80131 Naples, Italy

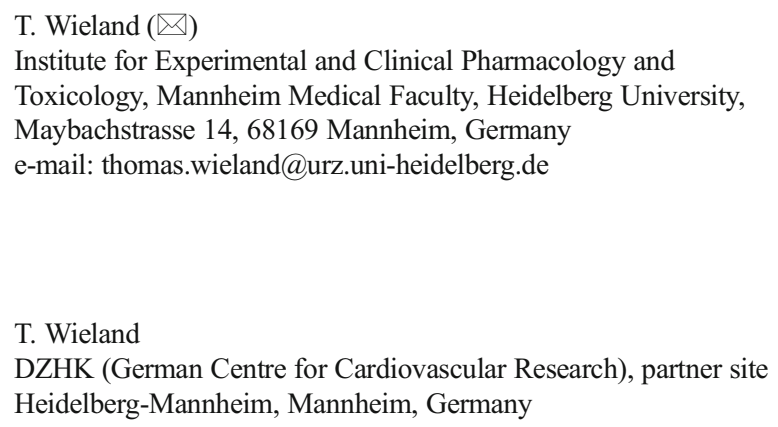


Nm23/awd proteins in development may explain its pathophysiological roles. Based on the reports made on the 9th International Congress of the NDP Kinase/Nm23/awd Gene Family in August 2013 in Boston, USA, experts in the field have summarized their ideas and views in review articles or contributed novel original research to a special issue of Naunyn-Schmiedeberg's Archives of Pharmacology. Within this editorial article, we propose a novel, potentially unifying hypothesis, which developed from studies from model organisms, but may help to understand the role of Nme proteins in cardiovascular diseases as well as in cancer.

\section{Developmental studies in model systems}

Studies of normal physiological functions of Nme genes using model organisms provide an excellent opportunity to unravel the underlying mechanism of Nme action. Indeed, studies using model systems have suggested a basic, unifying principle of Nme actions: Nme (or at least the group I members Nme1-4) is critical for vesicle and macromolecular transport, and Nme proteins perform this cellular function by acting as a scaffold.

\section{Drosophila melanogaster}

The only ortholog of the Nme genes in Drosophila, abnormal wing discs $(a w d)$, was discovered soon after the human Nmel (also known as $\mathrm{Nm} 23 \mathrm{H1}$ or NDPK A) metastasis suppressor activity was identified (Dearolf et al. 1988; Nallamothu et al. 2009; Steeg et al. 1988). Early studies in Drosophila showed that awd mutant larval brain exhibited mitotic defects correlated with defective microtubule polymerization (Biggs et al. 1990). Subsequently, awd has been implicated in the process of endocytosis in multiple tissues, including neurotransmitter uptake at the neuromuscular junctions (Krishnan et al. 2001), surface receptor internalization that modulates the chemotaxis response in tracheal cell and border cell migration (Dammai et al. 2003; Nallamothu et al. 2008), recycling of adherens junction components (Woolworth et al. 2009), and promotion of early-to-late endosome transition that is critical for Notch signaling in follicle cells and in imaginal discs (Ignesti et al. 2014). These endocytic functions were associated with the functions of dynamin and Rab5, suggesting a GTP-supplier function for these monomeric GTPases.

Interestingly, awd protein activity is negatively regulated by the kinase action of $5^{\prime}$ adenosine monophosphate-activated protein kinase (AMPK) (Onyenwoke et al. 2012). AMPK is a key regulator of cellular energy homeostasis (Hardie et al. 2003). It is activated during starvation. Previous studies have shown that $A M P K \alpha$ mutation could cause epithelial disruption and proliferation in the follicle cells but only under energy stress (Mirouse et al. 2007). Since loss of awd results in de- localization of adherens junction and breakdown of epithelial characteristics (Woolworth et al. 2009), the AMPK-awd axis may the key component in the regulation of nutrientdependent epithelial integrity.

\section{Caenorhabditis elegans}

Like Drosophila, C. elegans has a single Nme gene named $n d k-1$. Knockout of $n d k-1$ displayed sterility and a protruding vulva (Masoudi et al. 2013). Vulva development in C. elegans is largely determined by the canonical MAP kinase signaling. Epistasis study demonstrated that $n d k-1$ acts downstream of, or in parallel to, lin-45, the ortholog of the proto-oncogene serine/threonine-protein kinase Raf, and upstream of mek-2 and $m p k-1$, the orthologs of the mitogen-activated kinases $M E K$ and mitogen-activated protein kinase (MAPK), respectively. This placed the $n d k-1$ function at the same level as the kinase suppressors of $\mathrm{ras}(\mathrm{Ksr})$. Ksr encodes a scaffold protein that coordinates the MAPK relay system. Interestingly, it has been shown that mammalian Nmel protein binds Ksr and can function as a protein kinase for this scaffold (Hartsough et al. 2002). However, in mammalian cells, the phosphorylation is inhibitory, while in C. elegans, the interaction between $n d k-1$ and $K s r$ promotes MAPK signaling. Such difference may reflect different tissue context, although whether the worm $n d k-1$ protein can phosphorylate $K s r$ has yet to be determined.

In subsequent studies (Fancsalszky et al. 2014), the TakácsVellai group also discovered that $n d k-1$ is additionally involved in the migration of distal tip cell and engulfment and clearance of apoptotic corpses by gonadal sheath cells. These functions were placed downstream of ced-10, the ortholog of the monomeric GTPase Rac1, and showed a genetic interaction with $d y n$, the ortholog of the monomeric GTPase dynamin.

\section{Danio rerio}

The zebrafish is an excellent developmental model for organogenesis, because of the transparent body of the animal. Taking advantage of this model, Wieland et al. have shown that association of Nme2 (NDPK B) with the G protein $\beta \gamma$ dimer $(G \beta \gamma)$ is required for $G$ protein function in vivo (Hippe et al. 2009). This function in turn is critical for cardiac contractility, as Nme2, but not Nme1, knockdown resulted in cardiac phenotype characterized by a severely impaired cardiac contractility of both chambers of the heart, pericardial edema, and bradycardia (Hippe et al. 2011b). Such phenotype is linked with the failure of heterotrimeric $G$ protein subunits and their resident caveolae to be transported to the cell surface. Indeed, Nme 2 was found to associate with caveolae in normal cells (Hippe et al. 2011a; Hippe et al. 2011b).

More recently, the same laboratory also demonstrated that zebrafish larvae depleted of Nme2 displayed severe 
malformations specifically in vessels formed by angiogenesis. Importantly, a similar phenotype was observed in Nme2-deficient mice when the animals were subjected to oxygeninduced retinopathy. In this model, the number of preretinal neovascularizations in Nme2 (-/-) mice was strongly reduced in comparison with wild-type littermates (Feng et al. 2014). This defect may be correlated with the observation that Nme2 depletion impaired vascular endothelial growth factor (VEGF)-induced sprouting and hampered the VEGFinduced spatial redistributions of the VEGF receptor type 2 (VEGFR2) and VE-cadherin at the plasma membrane.

\section{Mus musculus}

Somewhat surprising, the mice deficient in the Nmel or the Nme2 gene have not yielded profound developmental defects, which is likely due to Nme isoform redundancy and/or compensatory mechanisms. Nmel (-/-) females cannot feed their pups as a result of growth retardation of the mammary glands and defects in the final step of mammary duct maturation of the nipple leading to duct obstruction (Deplagne et al. 2011).

Nme2 (-/-) mice are phenotypically normal at birth with a normal life span. They exhibit, however, a mild impairment of heart contractility at the age of 6 months or older. Although $\mathrm{T}$ and $\mathrm{B}$ cell development is normal in Nme2 (-/-) mice, $\mathrm{K}_{\mathrm{Ca}} 3.1$ channel activity and cytokine production are markedly defective in T helper 1 (Th1) and Th2 cells (Di et al. 2010). This phenotype is consistent with the previous finding that the Nme2 protein activates the potassium channel $\mathrm{K}_{\mathrm{Ca}} 3.1$ via histidine phosphorylation of the $\mathrm{C}$ terminus of the channel. This activation is required for $\mathrm{T}$ cell receptor-stimulated $\mathrm{Ca}^{2+}$ influx and proliferation of activated naive human CD4 T cells (Srivastava et al. 2006a).

Interestingly, Nmel(-/-); Nme2(-/-) double knockout mice are undersized, die perinatally, and exhibit a spectrum of hematological phenotypes including severe anemia, impaired maturation of erythrocytes, and abnormal hematopoiesis in the liver and bone marrow (Postel et al. 2009). The underlying molecular and cellular defects of this phenotype are not yet clear, but it is reasonable to speculate that defective chemotactic signaling regulated by receptor trafficking may be involved.

\section{Functions of the Nme family gene products related to cardiovascular disease}

Especially, Nme2 has been associated with functions in the cardiovascular system. Hippe et al. 2007 reported that Nme2 forms a complex with the $\beta$ subunit of the heterotrimeric $G_{s}$ protein in cardiomyocytes thereby regulating cardiac contractility. In a subsequent study, it was found that two distinct functions of Nme2 are involved in that regulation (Hippe et al. 2011a). One requires the histidine kinase activity which phosphorylates His266 in G $\beta$ (Cuello et al. 2003) and feeds into a phosphorelay fueling GTP for G protein activation. The second is apparently a scaffold function regulating the formation of caveolae which does not require enzymatic activity but complex formation with caveolins (Hippe et al. 2011a).

Nme2 as protein histidine kinase

As outlined in the review by Attwood and Wieland (2014), phosphorylation and dephosphorylation of protein histidine residues is quite common in signal transduction pathways in prokaryotes and lower eukaryotes, like yeast fungi and plants. In recent years, increasing evidence has been presented that $N m e 2$ can act as protein histidine kinase in mammals. The so far described few substrates of the Nme2, the channels $\mathrm{K}_{\mathrm{Ca}} 3.1$ and TRPV5 (Cai et al. 2014; Srivastava et al. 2006b), the G protein $\beta$ subunit (Cuello et al. 2003), and annexin 1 (Muimo et al. 2000) fall into at least two subgroups. The histidine phosphorylation of the channels follows the classical paradigm in which phosphorylation of a protein alters its confirmation and/or activity. Both channels exhibit higher open probability upon histidine phosphorylation, and this can be reversed upon dephosphorylation by the phosphohistidinespecific phosphatase PHP. As mentioned above, the importance of the regulation of these channels has been shown in mouse models (Cai et al. 2014; Di et al. 2010). Although also a substrate for PHP (Maurer et al. 2005), histidinephosphorylated $G \beta$ does not show altered activity and thus does not belong to the first category. His 266 in $G \beta$ apparently serves as a storage site for a high energetic phosphate group which can be retransferred onto GDP. The newly formed GTP is subsequently used to activate the heterotrimeric $G$ protein (Hippe et al. 2007).

\section{Nme2/caveolin interaction}

The association of caveolin-1 and caveolin-3 with Nme2 has first been detected in the zebrafish but later confirmed also in mammalian cells (Hippe et al. 2009). Accordingly, Nme2 as well as caveolin-3 (the prominent caveolin isoform in striated muscle) depleted zebrafish exhibit an impaired cardiac contractility (Hippe et al. 2011b; Hippe et al. 2009). Interestingly, the Nme2 knockdown in the zebrafish also impaired vessel formation by angiogenesis, a phenotype also seen under pathological conditions in Nme2 (-/-) mice (Feng et al. 2014). Apparently, the VEGF-induced spatial redistribution of the VEGFR2 is attenuated in Nme2-deficient endothelial cells. As the VEGFR2 resides in caveolae and the absence of caveolin-1 causes endothelial dysfunction as well as angiogenesis defects (Lin et al. 2007; Sonveaux et al. 2004), it is very likely that these defects are also related to the disturbed 
Nme2/caveolin interaction. Caveolin oligomers are already formed in the endoplasmic reticulum (Hayer et al. 2010). Thus, the reported facilitation of coat protein complex II (COPII)-dependent vesicular transport from ER exit sites by Nme2 (Kapetanovich et al. 2005) highlights a localization where protein complexes of $N m e 2$ with caveolins might assemble.

\section{Cancer-related functions of the Nme gene family}

\section{Nme1 as metastasis suppressor}

Metastasis is the movement of tumor cells from their initial site of origin to distant sites of the body and their progressive colonization of those sites. Metastases, by direct organ compromise or by complications of their treatment, are the major cause of cancer mortality. Differential expression of the Nme gene family was first identified in experimental melanoma metastasis. Nmel was more highly expressed in poorly metastatic sublines of the K-1735 murine melanoma than in related, highly metastatic sublines (Steeg et al. 1988). Transfection of Nmel into a highly metastatic melanoma line had no effect on primary tumor size but significantly reduced metastasis (Leone et al. 1991), the founding definition of a metastasis suppressor gene. Multiple confirmatory studies have been published in several cancer histologies (reviewed in Marino et al. (2012)), excluding leukemias, lymphomas, and neuroblastoma. Upon developing chemically induced liver cancer, Nme1-deficient mice formed significantly greater lung metastases than wild-type mice (Boissan et al. 2005), confirming a metastasis suppressor activity. Recent articles have expanded the breadth of metastasis suppression to Nmel in UV radiation-induced melanoma (Jarrett et al. 2013) and lung cancer (Fan et al. 2013) and to Nme3 (also named Nm23$D R$ ) in colorectal cancer (Qu et al. 2013). The function of Nmel has also expanded to some aspects of tumorigenesis (Jarrett et al. 2011). The potential role of Nme2 in tumorigenesis and metastasis is discussed in the reviews by Li et al. (2014) and Chowdhury (2014), respectively, in this issue of Naunyn-Schmiedeberg's Archives of Pharmacology.

Multiple aspects of metastasis have been implicated in Nmel suppression. Chiefly studied is tumor cell motility and invasion, the latter being traversal of an extracellular matrix. Invasion involves reversible changes in cell adhesion, motility, and proteolysis, often fueled by gene expression changes in the epithelial-mesenchymal transition (EMT). Surprisingly, no single set of pathways has been shown to be Nmel-dependent. Rather, a bewildering host of adhesion molecules (Boissan et al. 2010; Fournier et al. 2002; Kaetzel et al. 2014), motility factors, signaling pathways (Hartsough et al. 2002; Masoudi et al. 2013; Murakami et al. 2008; Otero 1997;
Otsuki et al. 2001; Roymans et al. 2000; Seong et al. 2007; Tanaka et al. 2012; You et al. 2014), proteolytic events (Khan et al. 2001), EMT hallmarks (Zhao et al. 2013), and other transcriptional programs (Horak et al. 2007) have been functionally linked to Nmel. A new, important finding showed that lysosomal cysteine cathepsins degraded Nmel proteins under the direction of $\mathrm{C}-\mathrm{Abl}$ and $\mathrm{Arg}$, limiting invasiveness (Fiore et al. 2014). That invasion and motility may be fundamental to Nme1's biological effects is supported by reports that its orthologs regulate these processes in Drosophila and C. elegans (Fancsalszky et al. 2014; Nallamothu et al. 2008).

Colonization of a distant site is also a fundamental part of cancer metastasis and may be the most amenable to translational development. For many cancer patients, evidence of initial spread is apparent at the time of initial diagnosis and surgery, such as involved lymph nodes. Thus, development of a motility or invasion inhibitor may be unusable since it has already occurred. Colonization of a distant site, evidenced by imaging, may have started but remains incomplete in many cancer patients. Experimental metastasis assays, in which tumor cells are inoculated into the circulation and bypass initial invasion steps, confirmed a metastasis suppressor activity for Nme1. Intravidal microscopy showed that control and Nmel transfectants of a breast cancer cell line reached the lung at comparable rates but that Nme1-overexpressing tumor cells survived in a distant organ more poorly (Horak et al. 2007).

Nme1 protein may interrupt the metastasis process by binding metastasis-promoting proteins in a scavenger like function. The number of validated protein/protein interactions (PPI) of the Nme protein family is large and growing. It includes viral proteins capable of causing invasion and metastasis (Banerjee et al. 2014; Murakami et al. 2005; Qin et al. 2011; Subramanian et al. 2001), oncogenes (Fishbach and Settleman 2003; Ignesti et al. 2014; Iwashita et al. 2004; Jarrett et al. 2013; Murakami et al. 2008), and other factors promoting aggressiveness and metastasis (D'Angelo et al. 2004; Horak et al. 2007; Reymond et al. 1999). Some of these interactions were disputed as they relied exclusively on the use of antibodies whose specificity was suspect. Alternatively, interactions of Nmel protein and other proteins may be indirect, part of a signaling complex. But even when reliable antibodies are available, the fact that two proteins can be coprecipitated from cell lysates does not ensure that they exist in a complex in a given intact cells. Cell lysis, for example, may disrupt subcellular compartmentalization and thus allow for PPIs actually not present in the native environment. For these reasons, independent lines of evidence should be presented to allow for the conclusion that two proteins are part of a larger protein complex and actually interact. An example for many of such independent lines of evidence would be the binding of h-prune to Nme1 and Nme2 in mammalian tumorigenic cells. Starting from a genetic interaction model based on homology 
to prune and Drosophila awd (Reymond et al. 1999), it was found that the phosphorylation of NmeI serine residues 122 and 125 by casein kinase I was regulating this PPI (Garzia et al. 2008), thereby enhancing WNT signaling and vesicular trafficking. The resulting increase in cell motility finally propagates cell escape from the primary tumor site and metastases (Carotenuto et al. 2014; Carotenuto et al. 2013; Garzia et al. 2008). In a review in this issue of Naunyn-Schmiedeberg's Archives of Pharmacology (Vlatkovic et al. 2014), the authors raised a pivotal question to all PPI studies, "the issue of false or incorrect syllogisms in PPI functional studies." Based on the arguments raised by Vlatkovic et al., the manifold of proposed interactions of Nme proteins with other proteins have to be carefully reevaluated for mis- or overinterpretation of the actual data. Often, the proposed direct interaction is more a "tip of an iceberg" situation where one partner is sitting on the top; the others, although detected by the used functional assays, are located somewhere else. Such results therefore give only very limited insights in the complex situation "below the surface of the water" (Galasso and Zollo 2009). Therefore, systems biology analyses based on in vivo observations may be an appropriate approach to validate the hypotheses regarding the multiple Nme protein family interaction partners and the related functions.

Another potential contribution of the Nme family to cancer progression lies in its interaction with DNA causing genomic instability (Kaetzel et al. 2014). The disruption of an Nme ortholog in E. coli was reported to produce a mutator phenotype and thus was opening research in that field ( $\mathrm{Lu}$ et al. 1995). Due to artifactual binding of Nme to DNA and DNAbinding proteins, this line of research has been fraught with missteps but, recently, some consistent patterns have emerged. Interactions of Nme with dynamin have been reported in multiple species and may extend to other aspects of the endocytosis, e.g., Rab5-dependent processes (Baillat et al. 2002; Dammai et al. 2003; Ignesti et al. 2014). The knockdown of Nmel in vitro caused abnormal chromosomal ploidy resulting from a failure in cytokinesis (Conery et al. 2010), which can be attributed to the provision of GTP (Boissan et al. 2014). As discussed by Kaetzel et al. 2014, Nmel apparently increases genetic stability in melanoma, possibly by a $3^{\prime}-5^{\prime}$ exonuclease activity as well as NTP fueling to DNA polymerases. In line with this interpretation, Nmel promoted the repair of UV-induced DNA damage to limit melanoma formation (Jarrett et al. 2011; Yang et al. 2009; Zhang et al. 2011).

In addition to PPI and DNA interactions, also the protein kinase activity of Nme1 is discussed to be relevant for its antimetastatic actions. Compared to Nme2, there are even fewer known substrates of the kinase activity of Nme1. ATP citrate lyase, the first confirmed substrate of Nmel acting as protein histidine kinase (Wagner and $\mathrm{Vu}$ 1995), is also a substrate to PHP. Its phosphorylation correlates to higher enzymatic activity and to the viability of neuronal cells in culture (Klumpp et al. 2009). Nevertheless, evidence from in vivo models supporting the importance of this regulation is missing. A second substrate for Nmel is KSR which is however phosphorylated on an important serine residue (Hartsough et al. 2002). As the phosphorylation of KSR regulates its scaffold function, the finding that in $C$. elegans the interaction of KSR with Nmel is relevant for Ras activation (Masoudi et al. 2013) highlights the possibility that Nme isoenzymes might also be important kinases on other amino acid side chains. Lapek et al. (2014) describe in this issue of Naunyn-Schmiedeberg's Archives of Pharmacology an unbiased screen for so far unidentified phosphorylation on histidine and aspartic acid residue in proteins in a prostatic human epithelial cell model in non-tumorigenic, tumorigenic, and metastatic state. In the latter, the expression of human Nme1 (and Nme2) was reduced. Although it is not clear that the loss of phosphorylated proteins detected in the tumorigenic and metastatic cells is due to the reduced presence of Nme isoforms, some of the proteins might turn out to be indeed so far unknown protein substrates for phosphorylation by Nme.

Translational advances in cancer therapy based on targeting Nme-dependent processes

Ever since its discovery in 1988, a goal of Nme research has been to elevate its expression in micrometastatic tumor cells and prevent their metastatic colonization in cancer patients. An inhibition of the Nme enzymatic activity by small molecule inhibitors was initially intended, but the available polyphenols such as ellagic acid (Buxton 2008), although widely discussed to be beneficial in cancer therapy, are unspecific kinase inhibitors and show low potency. Gene therapy approaches were successful preclinically (Li et al. 2006; Li et al. 2009) but remain clinically intractable. A variety of alternative approaches have been pursued. First, elevation of tumor cell expression of $\mathrm{Nmel}$ protein was demonstrated in vitro and in vivo by high-dose medroxyprogesterone acetate (MPA) (Ouatas et al. 2002; Ouatas et al. 2003), with concomitant inhibition of metastasis (Palmieri et al. 2005). The validity of this approach as therapeutic option was tested in a phase II trial for advanced breast cancer. The experimental regimen could not be validated as patients failed to achieve the necessary plasma levels of MPA (Miller et al. 2014). Other compounds have been reported to elevate tumor cell Nmel expression as well (Jiang et al. 1988; Lin et al. 2002; Liu et al. 2000; Natarajan et al. 2002) and thus are additional candidates at least for preclinical testing. A cell permeable Nme1 construct suppressed development of pulmonary metastases in mice and diminished already established metastases, with a prolongation of overall survival (Lim et al. 2011). A peptide that disrupts the interaction of Nmel and h-Prune has been identified, and preclinical studies were performed in breast and prostate cancers as well as neuroblastoma (Carotenuto 
et al. 2014; Carotenuto et al. 2013; D'Angelo et al. 2004). The results obtained by Carotenuto et al. (2014) (presented in this issue of Naunyn-Schmiedeberg's Archives of Pharmacology) which showed the effectiveness and safety of the peptide expression treatment in a mouse prostate cancer model of metastasis support its use in further clinical testing. For example, an in situ delivery of the peptide to patients affected by prostate cancer and undergoing prostatectomy would present an interesting therapeutic option.

Another translational approach is based on the identification of genes which expression patterns were inversely related to that of Nme1 protein. The lysophosphatidic acid receptor 1 (LPA1, EDG2, LPAR1) was inversely expressed to Nme1 in multiple cancer cell lines as well as in human breast tumors. The use of LPA1 antagonist was validated in two preclinical models to suppress metastasis in breast cancer without effecting primary tumor formation (Marshall et al. 2012). The analysis of proliferation rates and activation of the MAP kinase pathway in micrometastatic tumor cells in distant organs suggested an induction of metastatic dormancy as underlying mechanism. Orally available forms of this compound are now in advanced preclinical testing. Other inverse expression correlates of Nmel have been reported and stand as far as preclinical research leads (Bosnar et al. 2006; Ma et al. 2008; McCorkle et al. 2014; Zhao et al. 2004). The identification of novel metastasis suppressive or metastatic colonization preventive drug candidates will require testing in adjuvant setting trials. These trials are large, costly, and lengthy. Newer proposed trial designs may facilitate such testing (Steeg 2012).

\section{Future perspectives: a potential unifying theme}

The function of Nme protein as an endocytic factor was noted more than 10 years ago in Drosophila (Dammai et al. 2003; Krishnan et al. 2001). More recent genetic studies have further supported a more general role in vesicular transport (Feng et al. 2014; Hippe et al. 2011a; Hippe et al. 2011b; Hippe et al. 2009). It is therefore reasonable to contemplate that elucidating the molecular mechanism underlying such ancestral physiological function could help clarify many of the current seemingly endless arrays of cellular functions. Some recent findings may point the way. As mentioned, Nme2 has been shown to be part of the COPII complex required for vesicle transport from the endoplasmic reticulum to the Golgi apparatus (Kapetanovich et al. 2005). The authors suggested that Nme2 participates in the formation of a proteinaceous scaffold along which ER exit sites are organized. Another possibility is that ER-to-Golgi transport requires microtubules (Presley et al. 1997). Interestingly, one of the earliest observed properties of Nme, in this case awd and the bovine NDPK, was its association with microtubules (Biggs et al. 1990;
Nickerson and Wells 1984). More directly related to endocytosis, it was recently demonstrated that Nmel (and Nme2) was localized at clathrin-coated pits and interacted with the proline-rich domain of dynamin. In vitro, Nme1 and Nme2 were recruited to dynamin-induced tubules, stimulated GTP loading on dynamin, and triggered fission in the presence of ATP and GDP (Boissan et al. 2014). This finding, combined with the intriguing property of Nme4 (a mitochondria-specific Nme protein) in bridging two lipid bilayers (Schlattner et al. 2014; Schlattner et al. 2013), could suggest a scaffolding role of the Nme proteins to bring together proteins and lipid components that are involved in vesicle fusion and/or fission. In line with this interpretation, Nme3 associated with membranous structures, most likely mitochondria (Negroni et al. 2000).

In a broader context, it is very likely that Nme proteins serve their myriad of cellular functions by playing the role of a scaffold. Depending of the partners in different tissue and subcellular contexts, the Nme scaffolds can exert different functions, which may include endocytosis, macromolecular transport, signal transduction, and various enzymatic functions including NTP supply, protein kinase, or nuclease activity. With this scaffold hypothesis, we also propose a potential unifying theme for many of the antimetastatic actions of Nme proteins consistent with their developmental roles: Likely, Nme proteins provide spatial and temporal control of signaling or modify the activity of other scaffold proteins. Thus, reports of Nme binding to multiple aspects of the cytoskeletal machinery may all involve a common motility-related activation scaffold. This raises the question whether the instability of metastatic tumor cells may be at least partially accounted for by the loss of organized scaffolding, setting established signaling pathways inherent in differentiation into disarray. If true, it will be important to understand the regulation of Nme expression levels as well as the properties which Nme proteins use to exert their scaffolding function. These hypotheses suggest a myriad of new studies that need to be undertaken with appropriate controls to address this potentially important Nme activity in vivo. As discussed herein for a variety of examples, developmental studies using model organisms with the help of advanced cell biology and proper systems biology may set the gold standard for future Nme-related research.

\section{References}

Attwood PV and Wieland T (2014) Nucleoside diphosphate kinase as protein histidine kinase. Naunyn Schmiedeberg's Arch Pharmacol. In press

Baillat G, Gaillard S, Castets F, Monneron A (2002) Interactions of phocein with nucleoside diphosphate kinase, Eps15, and dynamin I. J Biol Chem 277:18961-18966 
Banerjee S, Jha H and Robertson E (2014) Regulation of the metastasis suppressor Nm23-H1 by tumor viruses. Naunyn Schmiedeberg's Arch Pharmacol. In press

Biggs J, Hersperger E, Steeg PS, Liotta LA, Shearn A (1990) A drosophila gene that is homologous to a mammalian gene associated with tumor metastasis codes for a nucleoside diphosphate kinase. Cell 63: 933-940

Boissan M, Wendum D, Arnaud-Dabernat S, Munier A, Debray M, Lascu I, Daniel JY, Lacombe ML (2005) Increased lung metastasis in transgenic NM23-Null/SV40 mice with hepatocellular carcinoma. J Natl Cancer Inst 97:836-845

Boissan M, Wever OD, Lizarraga F, Wendum D, Poincloux R, Chignard N, Desbois-Mouthon C, Dufour S, Nawrocki-Raby B, Birembaut P et al (2010) Implication of metastasis suppressor NM23-H1 in maintaining adherens junctions limiting the invasive potential of human cancer cells. Cancer Res 70:7710-7722

Boissan M, Montagnac G, Shen Q, Griparic L, Guitton J, Romao M, Sauvonnet N, Lagache T, Lascu I, Raposo G et al (2014) Membrane trafficking. Nucleoside diphosphate kinases fuel dynamin superfamily proteins with GTP for membrane remodeling. Science 344: $1510-1515$

Bosnar MH, Bago R, Gall-Troselj K, Streichert T, Pavelic J (2006) Downstream targets of Nm23-H1: gene expression profiling of CAL 27 cells using DNA microarray. Mol Carcinog 45:627-633

Buxton IL (2008) Inhibition of Nm23H2 gene product (NDPK-B) by angiostatin, polyphenols and nucleoside analogs. Proc West Pharmacol Soc 51:30-34

Cai X, Srivastava S, Surindran S, Li Z, Skolnik EY (2014) Regulation of the epithelial $\mathrm{Ca}^{2+}$ channel TRPV5 by reversible histidine phosphorylation mediated by NDPK-B and PHPT1. Mol Biol Cell 25:1244 1250

Carotenuto M, Pedone E, Diana D, de Antonellis P, Dzeroski S, Marino N, Navas L, Di Dato V, Scoppettuolo MN, Cimmino F et al (2013) Neuroblastoma tumorigenesis is regulated through the Nm23-H1/hPrune C-terminal interaction. Sci Rep 3

Carotenuto M, Antonellis Pd, Chiarolla C, Attanasio C, Damiani V, Boffa I, Aiese N, Pedone E, Accordi B, Basso G et al (2014) A therapeutic approach to treat prostate cancer by targeting Nm23-H1/h-Prune interaction. Naunyn Schmiedeberg's Arch Pharmacol. In press

Chowdhury S (2014) Inhibition of telomerase activity by NME2: impact on metastasis suppression? Naunyn Schmiedeberg's Arch Pharmacol. In press

Conery AR, Sever S, Harlow E (2010) Nucleoside diphosphate kinase Nm23-H1 regulates chromosomal stability by activating the GTPase dynamin during cytokinesis. Proc Natl Acad Sci U S A 107:1546115466

Cuello F, Schulze RA, Heemeyer F, Meyer HE, Lutz S, Jakobs KH, Niroomand F, Wieland T (2003) Activation of heterotrimeric G proteins by a high energy phosphate transfer via nucleoside diphosphate kinase (NDPK) B and G $\beta$ subunits. Complex formation of NDPK B with $G \beta \gamma$ dimers and phosphorylation of His-266 in G $\beta$. J Biol Chem 278:7220-7226

Dammai V, Adryan B, Lavenburg KR, Hsu T (2003) Drosophila awd, the homolog of human $\mathrm{nm} 23$, regulates FGF receptor levels and functions synergistically with shi/dynamin during tracheal development. Genes Dev 17:2812-2824

D'Angelo A, Garzia L, Andre A, Carotenuto P, Aglio V, Guardiola O, Arrigoni G, Cossu A, Palmieri G, Aravind L et al (2004) Prune cAMP phosphodiesterase binds $\mathrm{nm} 23-\mathrm{H} 1$ and promotes cancer metastasis. Cancer Cell 5:137-149

Dearolf CR, Hersperger E, Shearn A (1988) Developmental consequences of awdb3, a cell-autonomous lethal mutation of drosophila induced by hybrid dysgenesis. Dev Biol 129:159-168

Deplagne C, Peuchant E, Moranvillier I, Dubus P, Dabernat S (2011) The anti-metastatic nm23-1 gene is needed for the final step of mammary duct maturation of the mouse nipple. PLoS One 6:e18645
Di L, Srivastava S, Zhdanova O, Sun Y, Li Z, Skolnik EY (2010) Nucleoside diphosphate kinase B knock-out mice have impaired activation of the $\mathrm{K}^{+}$channel $\mathrm{K}_{\mathrm{Ca}} 3.1$, resulting in defective $\mathrm{T}$ cell activation. J Biol Chem 285:38765-38771

Fan Y, Yao YB, Li L, Wu ZH, Xu F, Hou M, Wu H, Shen YL, Wan HS, Zhou QH (2013) nm23-H1 gene driven by hTERT promoter induces inhibition of invasive phenotype and metastasis of lung cancer xenograft in mice. Thorac Cancer 4:41-52

Fancsalszky L, Monostori E, Farkas Z, Pourkarimi E, Masoudi N, Hargitai B, Bosnar MH, Dezeljin M, Zsakai A, Vellai T et al (2014) NDK-1, the homolog of NM23-H1/H2 regulates cell migration and apoptotic engulfment in C. elegans. PLoS One 9:e92687

Feng Y, Gross S, Wolf NM, Butenschon VM, Qiu Y, Devraj K, Liebner S, Kroll J, Skolnik EY, Hammes HP et al (2014) Nucleoside diphosphate kinase $\mathrm{B}$ regulates angiogenesis through modulation of vascular endothelial growth factor receptor type 2 and endothelial adherens junction proteins. Arterioscler Thromb Vasc Biol 34: 2292-2300

Fiore LS, Ganguly SS, Sledziona J, Cibull ML, Wang C, Richards DL, Neltner JM, Beach C, McCorkle JR, Kaetzel DM et al (2014) c-Abl and Arg induce cathepsin-mediated lysosomal degradation of the NM23-H1 metastasis suppressor in invasive cancer. Oncogene 33: $4508-4520$

Fishbach M, Settleman J (2003) Specific biochemical inactivation of oncogenic ras proteins by nucleoside diphosphate kinase. Cancer Res 63:4089-4094

Fournier H, Dupe-Manet S, Bouvard D, Laconbe M, Marie C, Block M, Albiges-Rizo C (2002) Integrin cytoplasmic domain-associated protein 1a (ICAP-1a) interacts directly with the metastasis suppressor $\mathrm{nm} 23-\mathrm{H} 2$, and both proteins are targeted to newly formed cell adhesion sites upon integrin engagement. J Biol Chem 277: 20895-20902

Galasso A, Zollo M (2009) The Nm23-H1-h-Prune complex in cellular physiology: a 'tip of the iceberg' protein network perspective. Mol Cell Biochem 329:149-159

Garzia L, D'Angelo A, Amoresano A, Knauer SK, Cirulli C, Campanella C, Stauber RH, Steegborn C, Iolascon A, Zollo M (2008) Phosphorylation of nm23-H1 by CKI induces its complex formation with h-prune and promotes cell motility. Oncogene 27:1853-1864

Hardie DG, Scott JW, Pan DA, Hudson ER (2003) Management of cellular energy by the AMP-activated protein kinase system. FEBS Lett 546:113-120

Hartsough M, Morrison D, Salerno M, Palmieri D, Ouatas T, Mair M, Patrick J, Steeg P (2002) Nm23-H1 metastasis suppressor phosphorylation of Kinase suppressor of ras (KSR), via a histidine protein kinase pathway. J Biol Chem 277:32389-32399

Hayer A, Stoeber M, Bissig C, Helenius A (2010) Biogenesis of caveolae: stepwise assembly of large caveolin and cavin complexes. Traffic 11:361-382

Hippe HJ, Luedde M, Lutz S, Koehler H, Eschenhagen T, Frey N, Katus HA, Wieland T, Niroomand F (2007) Regulation of cardiac cAMP synthesis and contractility by nucleoside diphosphate kinase B/G protein $\beta \gamma$ dimer complexes. Circ Res 100:1191-1199

Hippe HJ, Wolf NM, Abu-Taha I, Mehringer R, Just S, Lutz S, Niroomand F, Postel EH, Katus HA, Rottbauer W et al (2009) The interaction of nucleoside diphosphate kinase B with $\mathrm{Gb} \beta \gamma$ dimers controls heterotrimeric G protein function. Proc Natl Acad Sci U S A 106:16269-16274

Hippe HJ, Abu-Taha I, Wolf NM, Katus HA, Wieland T (2011a) Through scaffolding and catalytic actions nucleoside diphosphate kinase B differentially regulates basal and $\beta$-adrenoceptor-stimulated cAMP synthesis. Cell Signal 23:579-585

Hippe HJ, Wolf NM, Abu-Taha HI, Lutz S, Le Lay S, Just S, Rottbauer W, Katus HA, Wieland T (2011b) Nucleoside diphosphate kinase B is required for the formation of heterotrimeric $\mathrm{G}$ protein containing caveolae. Naunyn Schmiedebergs Arch Pharmacol 384:461-472 
Horak CE, Lee JH, Elkahloun AG, Boissan M, Dumont S, Maga TK, Arnaud-Dabernat S, Palmieri D, Stetler-Stevenson WG, Lacombe ML et al (2007) Nm23-H1 suppresses tumor cell motility by downregulating the lysophosphatidic acid receptor EDG2. Cancer Res 67: 7238-7246

Ignesti M, Barraco M, Nallamothu G, Woolworth JA, Duchi S, Gargiulo G, Cavaliere V, Hsu T (2014) Notch signaling during development requires the function of awd, the drosophila homolog of human metastasis suppressor gene Nm23. BMC Biol 12:12

Iwashita S, Fujii M, Mukai H, Ono Y, Miyamoto M (2004) Lbc protooncogene product binds to and could be negatively regulated by metastasis suppressor nm23-H2. Biochem Biophys Res Commun 320:1063-1068

Jarrett S, Novak M, Dabernat S, Daniel J-Y, Mellon I, Zhang Q, Harris N, Ciesielski M, Fenstermaker R, Kovacic D et al (2011) Metastasis suppressor NM23-H1 promotes repair of UV-induced DNA damage and suppresses UV-induced melanomagenesis. Cancer Res 72:133-143

Jarrett SG, Novak M, Harris N, Merlino G, Slominski A, Kaetzel DM (2013) NM23 deficiency promotes metastasis in a UV radiationinduced mouse model of human melanoma. Clin Exp Metastasis 30: $25-36$

Jiang W, Hiscox S, Bryce R, Horrobin D, Mansel R (1988) The effects of n-6 polyunsaturated fatty acids on the expression of nm-23 in human cancer cells. Br J Cancer 77:731-738

Kaetzel D, Leonard M, Cook G, Novak M, Jarrett S, Yang X and Belkin A (2014) Dual functions of NME1 in suppression of cell motility and enhancement of genomic stability in melanoma. Naunyn Schmiedeberg's Arch Pharmacol. In press

Kapetanovich L, Baughman C, Lee TH (2005) Nm23H2 facilitates coat protein complex II assembly and endoplasmic reticulum export in mammalian cells. Mol Biol Cell 16:835-848

Khan M, Yasuda M, Higashino F, Haque S, Kohgo T, Nakmura M, Shindoh M (2001) nm23-H1 suppresses invasion of oral squamous cell carcinoma-derived cell lines without modifying matrix metalloproteinase- 2 and matrix metalloproteinase- 9 expression. Am J Pathol 158:1785-1791

Klumpp S, Faber D, Fischer D, Litterscheid S, Krieglstein J (2009) Role of protein histidine phosphatase for viability of neuronal cells. Brain Res 1264:7-12

Krishnan KS, Rikhy R, Rao S, Shivalkar M, Mosko M, Narayanan R, Etter P, Estes PS, Ramaswami M (2001) Nucleoside diphosphate kinase, a source of GTP, is required for dynamin-dependent synaptic vesicle recycling. Neuron 30:197-210

Lapek JD, Tombline G, Kellersberger KA, Friedman MR and Friedman AE (2014) Evidence of histidine and aspartic acid phosphorylation in human prostate cancer cells. Naunyn Schmiedeberg's Arch Pharmacol. In press

Leone A, Flatow U, King CR, Sandeen MA, Margulies IMK, Liotta LA, Steeg PS (1991) Reduced tumor incidence, metastatic potential, and cytokine responsiveness of nm23-transfected melanoma cells. Cell 65:25-35

Li J, Zhou J, Chen G, Wang H, Wang S, Xing H, Gao Q, Lu Y, He Y, Ma D (2006) Inhibition of ovarian cancer metastasis by adenoassociated virus-mediated gene transfer of $\mathrm{nm} 23-\mathrm{H} 1$ in an orthotopic transplantation model. Cancer Gene Ther 13:266-270

Li Z, Xiang J, Zhang W, Fan S, Wu M, Li X, Li G (2009) Nanoparticle delivery of anti-metastatic NM23-H1 gene improves chemotherapy in a mouse tumor model. Cancer Gene Ther 16:423-429

Li Y, Tong Y and Wong YH (2014) Regulatory functions of Nm23-H2 in tumorigenesis: insights from biochemical to clinical perspectives. Naunyn Schmiedeberg's Arch Pharmacol. In press

Lim J, Jang G, Kang S, Lee G, Nga D, Phuong D, Kim H, El-Rifai W, Ruley H, Jo D (2011) Cell-permeable NM23 blocks the maintenance and progression of established pulmonary metastasis. Cancer Res 71:7216-7225
Lin K, Wang W, Wu Y, Cheng S (2002) Activation of antimetastatic Nm23-H1 gene expression by estrogen and its a-receptor. Endocrinology 143:467-475

Lin MI, Yu J, Murata T, Sessa WC (2007) Caveolin-1-deficient mice have increased tumor microvascular permeability, angiogenesis, and growth. Cancer Res 67:2849-2856

Liu F, Qi H-L, Chen H-L (2000) Effects of all-trans retinoic acid and epidermal growth factor on the expression of nm23-H1 in human hepatocarcinoma cells. J Cancer Res Clin Oncol 126:85-90

Lu Q, Zhang X, Almaula N, Matthews C, Inouye M (1995) The gene for nucleoside diphosphate kinase functions as a mutator gene in Escheria coli. J Mol Biol 254:337-341

Ma W, Chen J, Xue X, Wang Z, Liu H, Wang T, Bai Y, Tang SC, Zhou Q (2008) Alteration in gene expression profile and biological behavior in human lung cancer cell line NL9980 by nm23-H1 gene silencing. Biochem Biophys Res Commun 371:425-430

Marino N, Nakayama J, Collins JW, Steeg PS (2012) Insights into the biology and prevention of tumor metastasis provided by the $\mathrm{Nm} 23$ metastasis suppressor gene. Cancer Metastasis Rev 31:593-603

Marshall J, Collins J, Nakayama J, Horak C, Liewehr D, Steinberg S, Albaugh M, Vidal-Vanaclocha F, Palmieri D, Barbier M et al (2012) Effect of inhibition of the lysophosphatidic acid receptor 1 (LPA1) on metastasis and metastatic dormancy in breast cancer. J Natl Cancer Inst 104:1306-1319

Masoudi N, Fancsalszky L, Pourkarimi E, Vellai T, Alexa A, Remenyi A, Gartner A, Mehta A, Takacs-Vellai K (2013) The NM23-H1/H2 homolog NDK-1 is required for full activation of Ras signaling in C. elegans. Development 140:3486-3495

Maurer A, Wieland T, Meissl F, Niroomand F, Mehringer R, Krieglstein J, Klumpp $S$ (2005) The $\beta$-subunit of $G$ proteins is a substrate of protein histidine phosphatase. Biochem Biophys Res Commun 334:1115-1120

McCorkle JR, Leonard MK, Kraner SD, Blalock EM, Ma DQ, Zimmer SG, Kaetzel DM (2014) The metastasis suppressor NME1 regulates expression of genes linked to metastasis and patient outcome in melanoma and breast carcinoma. Cancer Genomics Proteomics 11: 175-194

Miller KD, Althouse SK, Nabell L, Rugo H, Carey L, Kimmick G, Jones DR, Merino MJ, Steeg PS (2014) A phase II study of medroxyprogesterone acetate in patients with hormone receptor negative metastatic breast cancer: translational breast cancer research consortium trial 007. Breast Cancer Res Treat 148:99-106

Mirouse V, Swick LL, Kazgan N, St Johnston D, Brenman JE (2007) LKB1 and AMPK maintain epithelial cell polarity under energetic stress. J Cell Biol 177:387-392

Muimo R, Hornickova Z, Riemen CE, Gerke V, Matthews H, Mehta A (2000) Histidine phosphorylation of annexin I in airway epithelia. J Biol Chem 275:36632-36636

Murakami M, Lan K, Subramanian C, Robertson E (2005) Epstein-Barr nuclear antigen 1 interacts with Nm23-H1 in lymphoblastoid cell lines and inhibits its ability to suppress cell migration. J Virol 79: $1559-1568$

Murakami M, Menses P, Lan K et al (2008) The suppressor of metastasis Nm23-H1 interacts with the Rho family member and the pleckstrin homology domain of Dbl-1 to suppress migration. Cancer Biol Ther $5: 688$

Nallamothu G, Woolworth JA, Dammai V, Hsu T (2008) Awd, the homolog of metastasis suppressor gene $\mathrm{Nm} 23$, regulates drosophila epithelial cell invasion. Mol Cell Biol 28:1964-1973

Nallamothu G, Dammai V, Hsu T (2009) Developmental function of Nm23/awd: a mediator of endocytosis. Mol Cell Biochem 329:3544

Natarajan K, Mori N, Artemov D, Bhujwalla Z (2002) Exposure of human breast cancer cells to the anti-inflammatory agent indomethacin alters choline phospholipid metabolites and $\mathrm{Nm} 23$ expression. Neoplasia 4:409-416 
Negroni A, Venturelli D, Tanno B, Amendola R, Ransac S, Cesi V, Calabretta B, Raschella G (2000) Neuroblastoma specific effects of DR-nm23 and its mutant forms on differentiation and apoptosis. Cell Death Differ 7:843-850

Nickerson JA, Wells WW (1984) The microtubule-associated nucleoside diphosphate kinase. J Biol Chem 259:11297-11304

Onyenwoke RU, Forsberg LJ, Liu L, Williams T, Alzate O, Brenman JE (2012) AMPK directly inhibits NDPK through a phosphoserine switch to maintain cellular homeostasis. Mol Biol Cell 23:381-389

Otero A (1997) Copurification of vimentin, energy metabolism ensymes and a MER5 homolog with nucleoside diphosphate kinase. Identification of tissue-specific interactions. J Biol Chem 272: 14690-14694

Otsuki Y, Tanaka M, Yoshii S, Kawazoe N, Nakaya K, Sugimura H (2001) Tumor metastasis suppressor nm23H1 regulates Rac GTPase by interaction with Tiam1. Proc Natl Acad Sci U S A 98: 4385-4390

Ouatas T, Clare S, Hartsough M, DeLaRosa A, Steeg P (2002) MMTVassociated transcription factor binding sites increase $\mathrm{nm} 23-\mathrm{H} 1 \mathrm{me}-$ tastasis suppressor gene expression in human breast carcinoma cell lines. Clin Exp Metastasis 19:35-42

Ouatas T, Halverson D, Steeg P (2003) Dexamethasone and medroxyprogesterone acetate elevate $\mathrm{Nm} 23-\mathrm{H} 1$ metastasis suppressor expression in metastatic human breast carcinoma cells: new uses for old compounds. Clin Cancer Res 9:3763-3772

Palmieri D, Halverson D, Ouatas T, Horak C, Salerno M, Johnson J, Figg W, Hollingshead M, Hursting S, Berrigan D et al (2005) Medroxyprogesterone acetate elevation of Nm23-H1 metastasis suppressor expression in hormone receptor-negative breast cancer. J Natl Cancer Inst 97:632-642

Postel EH, Wohlman I, Zou X, Juan T, Sun N, D'Agostin D, Cuellar M, Choi T, Notterman DA, La Perle KM (2009) Targeted deletion of Nm23/nucleoside diphosphate kinase A and B reveals their requirement for definitive erythropoiesis in the mouse embryo. Dev Dyn 238:775-787

Presley JF, Cole NB, Schroer TA, Hirschberg K, Zaal KJ, LippincottSchwartz J (1997) ER-to-Golgi transport visualized in living cells. Nature 389:81-85

Qin ZQ, Dai L, Toole B, Robertson E, Parsons C (2011) Regulation of Nm23-H1 and cell invasiveness by Kaposi's sarcoma-associated herpesvirus. J Virol 85:3596-3606

Qu LJ, Liang L, Su JJ, Yang Z (2013) Inhibitory effect of upregulated DR-nm23 expression on invasion and metastasis in colorectal cancer. Eur J Cancer Prev 22:512-522

Reymond A, Volorio S, Merla G, Al-Maghtheh M, Zuffardi O, Bulfone A, Ballabio A, Zollo M (1999) Evidence for interaction between human PRUNE and nm23-H1 NDPKinase. Oncogene 18:72447252

Roymans D, Willems R, Vissenberg K, DeJonghe C, Groben B, Claes P, Lascu I, Bockstaele DV, Verbelen J, VanBroeckhoven C et al (2000) Nucleoside diphosphate kinase $\mathrm{b}(\mathrm{Nm} 23-\mathrm{R} 1 / \mathrm{NDPKb})$ is associated with intermediate filaments and becomes upregulated upon cAMPinduced differentiation of rat C6 glioma. Exp Cell Res 261:127-138

Schlattner U, Tokarska-Schlattner M, Ramirez S, Tyurina YY, Amoscato AA, Mohammadyani D, Huang Z, Jiang J, Yanamala N, Seffouh A et al (2013) Dual function of mitochondrial Nm23-H4 protein in phosphotransfer and intermembrane lipid transfer: a cardiolipindependent switch. J Biol Chem 288:111-121

Schlattner U, Tokarska-Schlattner M, Epand RM, Boissan M, Lacombe ML, Klein-Seetharaman J and Kagan VE (2014) Mitochondrial NM23-H4/NDPK-D: a bifunctional nanoswitch for bioenergetics and lipid signaling. Naunyn Schmiedeberg's Arch Pharmacol. In press

Seong HA, Jung H, Ha H (2007) NM23-H1 tumor suppressor physically interacts with serine-threonine kinase receptor-associated protein, a transforming growth factor-beta (TGF- $\beta$ ) receptor-interacting protein, and negatively regulates TGF- $\beta$ signaling. J Biol Chem 282: 12075-12096

Sonveaux P, Martinive P, DeWever J, Batova Z, Daneau G, Pelat M, Ghisdal P, Gregoire V, Dessy C, Balligand JL et al (2004) Caveolin1 expression is critical for vascular endothelial growth factorinduced ischemic hindlimb collateralization and nitric oxidemediated angiogenesis. Circ Res 95:154-161

Srivastava S, Choudhury P, Li Z, Liu G, Nadkarni V, Ko K, Coetzee WA, Skolnik EY (2006a) Phosphatidylinositol 3-phosphate indirectly activates $\mathrm{K}_{\mathrm{Ca}} 3.1$ via 14 amino acids in the carboxy terminus of $\mathrm{K}_{\mathrm{Ca}} 3.1$. Mol Biol Cell 17:146-154

Srivastava S, Li Z, Ko K, Choudhury P, Albaqumi M, Johnson AK, Yan Y, Backer JM, Unutmaz D, Coetzee WA et al (2006b) Histidine phosphorylation of the potassium channel $\mathrm{K}_{\mathrm{Ca}} 3.1$ by nucleoside diphosphate kinase $\mathrm{B}$ is required for activation of $\mathrm{K}_{\mathrm{Ca}} 3.1$ and $\mathrm{CD} 4$ T cells. Mol Cell 24:665-675

Steeg P (2012) The right trials. Nature 485:S58-59

Steeg PS, Bevilacqua G, Kopper L, Thorgeirsson UP, Talmadge JE, Liotta LA, Sobel ME (1988) Evidence for a novel gene associated with low tumor metastatic potential. J Natl Cancer Inst 80:200-204

Subramanian C, Cotter M, Robertson E (2001) Epstein-Barr virus nuclear protein EBNA-3C interacts with the human metastatic suppressor Nm23-H1: a molecular link to cancer metastasis. Nat Med 7:350355

Tanaka M, Kuriyama S, Aiba N (2012) Nm23-H1 regulates contact inhibition of locomotion, which is affected by ephrin-B1. J Cell Sci 125:4343-4353

Wagner PD, Vu ND (1995) Phosphorylation of ATP-citrate lyase by nucleoside diphosphate kinase. J Biol Chem 270:21758-21764

Vlatkovic N, Chang SH and Boyd MT (2014) Janus-faces of NMEoncoprotein interactions. Naunyn Schmiedeberg's Arch Pharmacol. In press

Woolworth JA, Nallamothu G, Hsu T (2009) The Drosophila metastasis suppressor gene $\mathrm{Nm} 23$ homolog, awd, regulates epithelial integrity during oogenesis. Mol Cell Biol 29:4679-4690

Yang MM, Jarrett SG, Craven R, Kaetzel DM (2009) YNK1, the yeast homolog of human metastasis suppressor NM23, is required for repair of UV radiation- and etoposide-induced DNA damage. Mutat Res Fundam Mol Mech Mutagen 660:74-78

You DJ, Park CR, Lee HB, Moon MJ, Kang JH, Lee C, Oh SH, Ahn C, Seong JY, Hwang JI (2014) A splicing variant of NME1 negatively regulates NF-kappa B signaling and inhibits cancer metastasis by interacting with IKK beta. J Biol Chem 289:17709-17720

Zhang Q, McCorkle JR, Novak M, Yang M, Kaetzel DM (2011) Metastasis suppressor function of NM23-H1 requires its 3'-5' exonuclease activity. Int J Cancer 128:40-50

Zhao H, Jhanwar-Uniyal M, Datta PK, Yemul S, Ho L, Khitrov G, Kupershmidt I, Pasinetti GM, Ray T, Athwal RS et al (2004) Expression profile of genes associated with antimetastatic gene: nm23-mediated metastasis inhibition in breast carcinoma cells. Int J Cancer 109:65-70

Zhao RZ, Gong L, Li L, Guo LL, Zhu DX, Wu ZH, Zhou QH (2013) nm23-H1 is a negative regulator of TGF-beta 1-dependent induction of epithelial-mesenchymal transition. Exp Cell Res 319:740-749 